\title{
Propriedades da madeira de cerne e alburno de Eucalyptus camaldulensis
}

\author{
Ana Carolina Silva Costa ${ }^{1 *}$, Camila Sanick Leal ${ }^{1}$, Larissa Carvalho Santos ${ }^{2}$, Ana Márcia Macedo La- \\ deira Carvalho ${ }^{2}$, Aylson Costa Oliveira ${ }^{1}$, Bárbara Luísa Corradi Pereira ${ }^{1}$ \\ ${ }^{1}$ Departamento de Engenharia Florestal, Universidade Federal de Mato Grosso, Cuiabá, Mato Grosso, Brasil. \\ 2 Departamento de Engenharia Florestal, Universidade Federal de Viçosa, Viçosa, Minas Gerais, Brasil.
}

\begin{abstract}
RESUMO Não há um consenso entre as indústrias produtoras de carvão sobre qual tipo de madeira é mais adequada, ou seja, se é desejável maior proporção de cerne ou de alburno. Portanto, o objetivo deste trabalho foi avaliar as propriedades da madeira de cerne e alburno de dois clones (I e II) de Eucalyptus camaldulensis, destinados à produção de carvão vegetal. A densidade básica, caracterização anatômica das fibras, composição química, teor de cinzas e poder calorífico da madeira foram avaliados. Para os dois clones avaliados, as porcentagens de cerne diminuíram no sentido base-topo da árvore enquanto as porcentagens de alburno aumentam, sendo que o clone I tinha maiores porcentagens de cerne. A madeira de alburno apresentou maiores valores médios para densidade básica, fração parede, largura e espessura da parede das fibras. Já a região do cerne destacou-se com maiores valores médios de diâmetro do lume das fibras e teores de lignina e extrativos. Para cinzas e poder calorífico, os valores foram semelhantes para os tratamentos, $0,14 \%$ e 4649,0 kcal $/ \mathrm{kg}$, respectivamente. Conclui-se que o clone II é o indicado para a produção de carvão.
\end{abstract}

Palavras-chave: carbonização; qualidade da madeira; densidade.

\section{Properties of heartwood and sapwood of Eucalyptus camaldulensis}

\begin{abstract}
There is not an agreement among charcoal producers on which type of wood is more suitable, that is, if it is most desirable proportion of heartwood or sapwood. Therefore, the objective of this study was to evaluate the properties of wood in the regions of heartwood and sapwood of two clones (I and II) of Eucalyptus camaldulensis, for the production of charcoal. Basic density, anatomical characteristics of the fibers, chemical composition, ash content and higher heating value of wood were evaluated. For the two clones evaluated, the heartwood percentages decreased from the bottom to the top of the tree, while the sapwood percentages increased, of which the clone I had higher heartwood percentages. Wood sapwood showed higher average values for basic density, cell wall fraction, width and thickness of fibers walls. Already the heartwood stood out with higher average values of lumen diameter of the fibers and lignin and extractives content. Regarding ash content and higher heating value, the values were similar for the treatments, $0.14 \%$ to $4649.0 \mathrm{kcal} / \mathrm{kg}$, respectively. In conclusion, the clone II is the most suitable for charcoal production.
\end{abstract}

Keywords: carbonization; wood quality; density.

\section{Introdução}

O gênero Eucalyptus tem-se destacado nos últimos anos pela grande diversidade de espécies e boa adaptação aos mais diversos ambientes. No Brasil, o gênero tem sido amplamente utilizado pelo setor florestal como substituto imediato de madeiras oriundas de florestas nativas como fonte de matériaprima para diversos usos (PROTÁSIO et al., 2013).
A adoção de práticas sustentáveis de manejo florestal proporcionou o desenvolvimento de uma tecnologia silvicultural de plantios florestais de Eucalyptus reconhecida no mundo, o que é fundamental na agregação da qualidade e valor ao produto final (OLIVEIRA et al., 2012). Há muitos materiais genéticos melhorados para o aprimoramento das propriedades tecnológicas da madeira, visando a produção de carvão vegetal de melhor qualidade. No entanto, novos estudos ainda são 
necessários para possibilitar o aprimoramento contínuo do gênero Eucalyptus (CASTRO et al., 2013).

Em 2014, os plantios com Eucalyptus ocuparam 5,56 milhões de hectares da área de árvores plantadas no país, o que representou 71,9\% do total (IBÁ, 2015). Ainda segundo este estudo, $15,2 \%$ do total da área com árvores plantadas pertencem aos segmentos de siderurgia a carvão vegetal. $\mathrm{O}$ consumo de carvão vegetal no Brasil, em 2014, alcançou 5,30 milhões de toneladas (IBÁ, 2015), sendo a produção brasileira praticamente toda destinada ao mercado interno apesar da exportação de vários produtos que integram ou derivam da cadeia produtiva do carvão, sendo os maiores consumidores as indústrias de ferro-gusa, aço e ferro-ligas.

Segundo Evangelista et al. (2010), dentre as espécies do gênero, o Eucalyptus camaldulensis Dehnh, é considerado adequado para zonas críticas de plantio, onde ocorrem deficiências hídricas e edáficas, situações estas, extremamente limitantes para o desenvolvimento de outras espécies. Castro et al. (2013) ao avaliarem a qualidade da madeira de clones de Eucalyptus destinados à produção de carvão vegetal, observaram que o Eucalyptus camaldulensis se destacou, com elevada densidade básica e poder calorífico superior. Desta forma, pesquisas relacionadas à avaliação das propriedades de clones de Eucalyptus camaldulensis para a produção de carvão vegetal são de grande importância.

Neste contexto, Tomazello Filho (1987) assegurou que existe uma significativa variação nas porcentagens de cerne e alburno ao longo do tronco entre as espécies de Eucalyptus, refletindo na fisiologia do crescimento das árvores e, principalmente, nas propriedades e na utilização da madeira. A quantificação das percentagens de cerne e alburno na madeira a ser destinada para a produção de carvão vegetal é necessária porque a variação destes percentuais está associada à secagem da madeira e à carbonização, influenciando o controle do processo e a qualidade do carvão (PEREIRA et al., 2013a).
Porém, há carência de estudos sobre a qualidade da madeira de cerne e alburno de Eucalyptus para a produção de carvão vegetal. Assim, ainda hoje, não há um consenso entre as indústrias produtoras de carvão sobre qual tipo de madeira é mais adequada, ou seja, se é desejável maior proporção de cerne ou de alburno. Portanto, estudos que avaliam as diferenças entre as propriedades da madeira de cerne e alburno auxiliarão na seleção de materiais genéticos que garantirão maior rendimento e qualidade do carvão produzido.

Diante do exposto, os objetivos desta pesquisa foram: (a) avaliar as porcentagens de cerne a alburno ao longo do tronco de dois clones de Eucalyptus camaldulensis; (b) avaliar as propriedades físicas e químicas da madeira nas regiões de cerne e do alburno; e, (c) indicar o mais apropriado para a produção de carvão vegetal.

\section{Material e Métodos}

\section{Material biológico e amostragem}

Foram utilizados dois clones de Eucalyptus camaldulensis, com 7,5 anos de idade, provenientes de um teste clonal pertencente a uma empresa florestal no município de Lassance MG, cultivados em espaçamento 3,8 x 2,4 metros.

O teste clonal encontrava-se no bioma cerrado que é caracterizado pela sazonalidade pronunciada, onde o verão se manifesta quente e úmido e o inverno, frio e seco. O solo predominante era o Latossolo de cor vermelha ou vermelhoamarelada. Foram selecionadas três árvores de diâmetro médio para cada clone. A seleção foi feita excluindo-se as árvores da borda e as que apresentavam defeitos visuais. As informações gerais são apresentadas na Tabela 1.

De cada árvore foram retirados seis discos de $10 \mathrm{~cm}$ de espessura, correspondentes a 0\%, DAP (diâmetro à altura do peito), $25 \%, 50 \%, 75 \%$ e $100 \%$ da altura comercial do tronco, até o diâmetro mínimo de $7 \mathrm{~cm}$ (com casca). 
Tabela 1. Clones de Eucalyptus camaldulensis utilizados no estudo.

Table 1. Eucalyptus camaldulensis clones used in the study.

\begin{tabular}{ccccccc}
\hline Cl. & Procedência & Ht & DAPcc & Csc & $\begin{array}{c}\text { IMA } \\
\text { cc }\end{array}$ & $\begin{array}{c}\text { IMA } \\
\text { sc }\end{array}$ \\
\hline I & $\begin{array}{c}\text { Plantar S.A/ } \\
\text { Curvelo, } \\
\text { MG }\end{array}$ & 23,9 & 15,41 & 17,0 & 39,6 & 32,8 \\
\hline & $\begin{array}{c}\text { Gerdau S.A/ } \\
\text { Três Marias, } \\
\text { II }\end{array}$ & 25,0 & 15,76 & 15,0 & 40,3 & 34,2 \\
\hline
\end{tabular}

$\mathrm{Cl}=$ Clone, $\mathrm{Ht}=$ altura total média $(\mathrm{m}), \mathrm{DAPcc}=$ diâmetro médio a $1,3 \mathrm{~m}$ de altura do solo com casca $(\mathrm{cm}), \mathrm{Csc}=$ percentagem de casca (\%), IMAcc e IMAsc = incremento médio anual volumétrico com casca e sem casca $\left(\mathrm{m}^{3} \cdot \mathrm{ha}^{-1} \cdot \mathrm{ano}^{-1}\right)$.

\section{Caracterização anatômica, física e química da}

\section{madeira}

Inicialmente, identificou-se, em cada disco, a região de transição entre cerne e alburno, com o auxílio de uma lupa com aumento de dez vezes, observando-se a alteração na cor e ocorrência de poros obstruídos por tilos no cerne. De uma extremidade à outra de cada disco, traçaram-se duas retas perpendiculares, passando pelo centro da medula. Foram feitas as medições do diâmetro total e do diâmetro do cerne com uma régua de $0,1 \mathrm{~cm}$ de precisão. Posteriormente, foram calculadas as porcentagens de cerne e alburno de cada disco.

Os discos referentes à altura do DAP foram utilizados para as análises anatômicas da madeira. Dos outros discos foram obtidas duas cunhas opostas, passando pela medula, utilizadas para determinação da densidade básica da madeira. $\mathrm{O}$ restante de cada disco foi seccionado, formando-se uma amostra composta destinada às demais análises.

Para a densidade básica da madeira e porcentagens de cerne e alburno a avaliação foi feita no sentido base-topo. A densidade básica da madeira foi determinada pelo método de imersão em água, de acordo com a norma ABNT NBR 11941 (ABNT, 2003).
Para individualização das fibras, as amostras foram acondicionadas com solução de peróxido de hidrogênio e ácido acético glacial, segundo o método preconizado por Dadswell (1972). Posteriormente, montaram-se lâminas temporárias e mediram-se a largura da fibra e o diâmetro do lume de 30 fibras por árvore, de acordo com IAWA (1989). Foram utilizados um microscópio óptico com câmera acoplada, sistema de aquisição de imagens, e o software Axio-Vision. A espessura da parede celular da fibra foi determinada matematicamente pela metade da diferença entre a largura da fibra e o diâmetro do lume. A fração parede (FP) foi estimada conforme Foelkel et al. (1975):

$$
\mathrm{FP}=\left(\left(2{ }^{\star} \mathrm{Ep}\right)\right) / \mathrm{Df}^{\star} 100
$$

Em que: $\mathrm{FP}=$ Fração parede; Ep = Espessura de parede, em $\mu \mathrm{m} ; \mathrm{Df}=$ Diâmetro de fibra, em $\mu \mathrm{m}$.

Para determinação do poder calorífico superior e teores de extrativos, lignina e cinzas, as amostras de madeira foram transformadas em serragem, utilizando-se um moinho de laboratório tipo Wiley, de acordo com a norma TAPPI 257 om52 (TAPPI, 2001). Para essas análises, utilizou-se a fração que passou pela peneira com malha de 40 mesh e ficou retida na peneira com malha de 60 mesh.

Os teores de extrativos foram determinados em duplicatas, de acordo com a norma TAPPI 204 om-88 (TAPPI, 2001), utilizando-se o método de determinação de extrativos totais, apenas substituindo o etanol/benzeno, pelo etanol/tolueno.

Os teores de lignina insolúvel foram determinados em duplicata pelo método Klason, modificado de acordo com o procedimento proposto por Gomide e Demuner (1986). A lignina solúvel foi determinada por espectrometria, conforme Goldschimid (1971), a partir da diluição do filtrado proveniente do procedimento para obtenção da lignina insolúvel. O teor de lignina total foi obtido por meio da soma dos valores de lignina solúvel e insolúvel. 
A porcentagem de cinzas na madeira foi determinada de acordo com a norma ABNT NBR 13999 (ABNT, 2003).

O poder calorífico superior da madeira foi determinado de acordo com a metodologia descrita pela norma da ABNT NBR 8633 (ABNT, 1984), em duplicatas, utilizando-se uma bomba calorimétrica adiabática IKA300. As amostras foram secas em estufa a $103 \pm 2^{\circ} \mathrm{C}$, até massa constante.

\section{Análises estatísticas}

O experimento foi analisado com base em um delineamento inteiramente casualizado em esquema fatorial duplo, com dois clones (I e II) e duas regiões do tronco (cerne e alburno), com três repetições (árvores por clone). Os dados foram submetidos aos testes de Lilliefors, para testar a normalidade, e Cochran, para testar a homogeneidade das variâncias. Em seguida os resultados foram submetidos à análise de variância (ANOVA), em 5\% de significância, para verificação das diferenças existentes entre os materiais avaliados.

Para avaliar as porcentagens de cerne e alburno na direção longitudinal do tronco, utilizou-se a análise de regressão. Com o auxílio do programa CurveExpert 1.4 (HYAMS, 2009), definiram-se modelos, selecionando-se aqueles com melhores índices estimadores, baseando-se no coeficiente de determinação $\left(\mathrm{R}^{2}\right)$, no erro padrão residual e na distribuição dos resíduos. Para verificar a significância da regressão, procedeu-se a análise de variância, a 5\% de significância, com base no coeficiente de determinação $\left(\mathrm{R}^{2}\right)$, significância da regressão, testados pelo teste F e pela significância dos coeficientes da regressão, testados pelo teste " $t$ ” de Student. As análises estatísticas foram realizadas com o auxílio do software STATISTICA 8.0 (STATSOFT, 2007).

\section{Resultados e Discussão}

Na Figura 1 observam-se as porcentagens das regiões de cerne e alburno, dos dois clones, ao longo do tronco.

Para os dois clones avaliados, houve um decréscimo na quantidade de cerne no sentido longitudinal da árvore, e consequentemente, aumento na quantidade de alburno. Isso pode ser explicado devido à participação das camadas recémformadas de madeira, que vão aumentando gradativamente da base para o topo do fuste. Assim, existe mais madeira jovem nas posições mais altas, e como o desenvolvimento do cerne acompanha o avanço da idade do lenho, sua proporção é maior onde o lenho é mais velho, ou seja, na base da árvore.

O clone I apresentou maior porcentagem de cerne ao longo do fuste, até a altura de $75 \%$, quando comparado ao clone II. Em média, a porcentagem de cerne do clone II foi $35 \%$ menor que do clone I. Essas diferenças podem ser explicadas, provavelmente, pela adaptação dos clones ao local de plantio.

Na produção de carvão vegetal, as porcentagens de cerne e alburno afetam expressivamente a etapa inicial, caracterizada pela secagem da madeira (PEREIRA et al., 2013a). Com relação ao cerne, uma maior quantidade pode dificultar a secagem, já que este é impermeável, principalmente devido à obstrução dos vasos por tilos, o que dificulta o transporte de água da parte mais interna para a mais externa da madeira (GALVÃO; JANKOWSKY, 1985). Já o alburno, devido à sua maior permeabilidade, normalmente apresenta uma secagem mais rápida, quando comparado ao cerne. Assim, ao considerar somente a fase inicial da carbonização, clones com maiores quantidades de alburno, como o clone II, seriam mais adequados para a produção de carvão vegetal.

A densidade básica diferiu apenas para o fator região da madeira. Ou seja, não houve diferenças significativas entre a densidade básica dos clones I e II. Os valores médios da densidade básica da madeira de cerne e do alburno foram 562,80 $\mathrm{kg} \cdot \mathrm{m}^{-3}$ e $605,40 \mathrm{~kg} \cdot \mathrm{m}^{-3}$, respectivamente. Houve, portanto, 
uma diferença de 7\% na densidade da madeira das diferentes regiões.

Os valores observados são semelhantes aos encontrados na literatura para clones do gênero Eucalyptus destinados à produção de carvão vegetal (SANTOS et al., 2011; PEREIRA et al., 2012; CARNEIRO et al., 2014). Arantes et al. (2013) ao avaliarem a densidade da madeira de Eucalyptus spp. também verificaram a ocorrência de menores valores de densidade do lenho na região do cerne com aumento gradativo em direção ao alburno.

A madeira como matéria-prima para carvão vegetal deve apresentar certas características que vão contribuir para um melhor desempenho da carbonização e da qualidade do produto final. De acordo com Carneiro et al. (2014), a densidade da madeira mais elevada resulta em maiores densidade e resistência mecânica do carvão vegetal. Assim, para os clones avaliados, a região do alburno se destacou. Ou seja, devem-se preferir materiais genéticos com maior proporção de alburno, quando observada apenas a densidade da madeira.

$\mathrm{Na}$ análise anatômica das fibras, houve diferença significativa tanto em nível de clone quanto de região da madeira, para os parâmetros diâmetro do lume e fração parede (Tabela 2), porém, a interação entre os fatores clone e região da madeira não foi significativa.

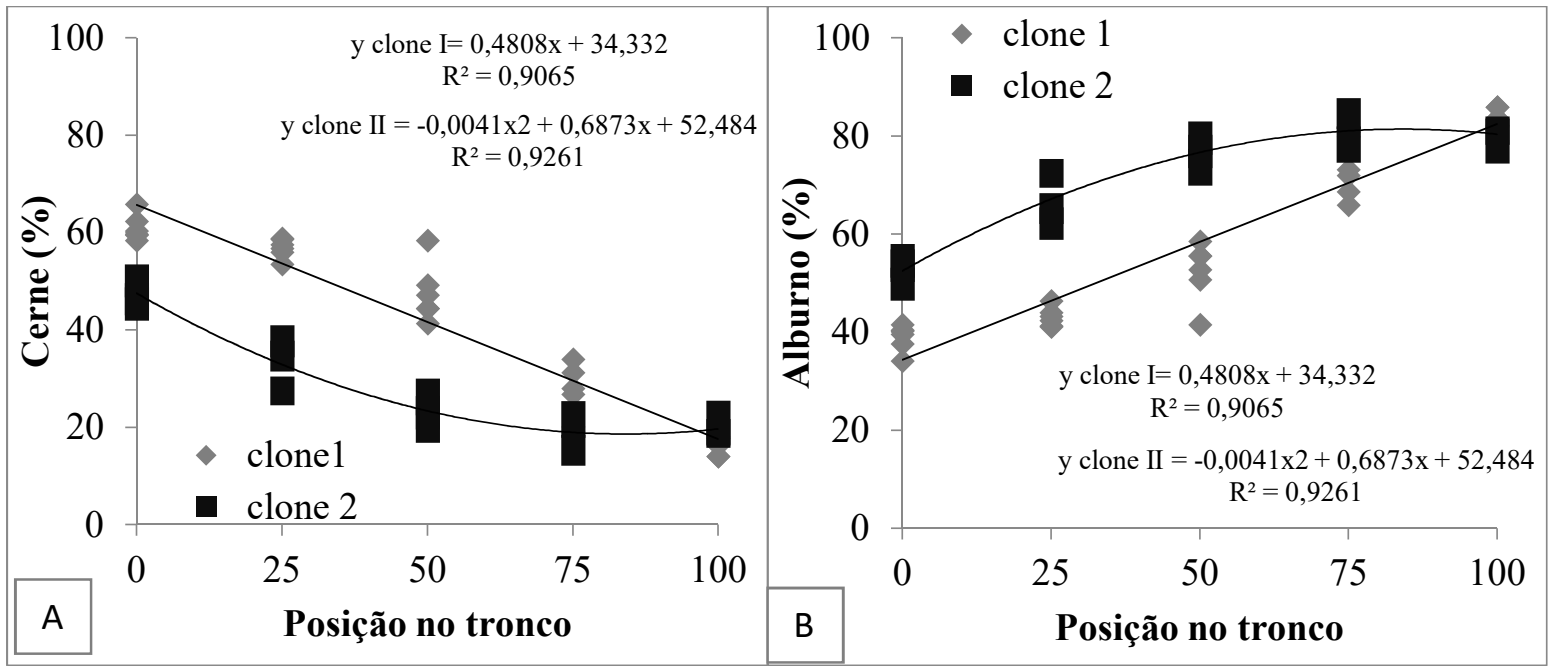

Figura 1. Valores observados e estimados das porcentagens de cerne (A) e alburno (B) dos clones de Eucalyptus camaldulensis ao longo do tronco.

Figure 1. Observed and estimated values of Eucalyptus camaldulensis heartwood (A) and sapwood (B) along the trunk.

Tabela 2. Diâmetro do lume das fibras $(\mu \mathrm{m})$ e fração parede, em função dos clones e regiões da madeira

Table 2. Diameter of fibers lumen and cell wall fraction as a function of the clones and the wood regions.

\begin{tabular}{ccc|cr}
\hline & \multicolumn{2}{c|}{ Clone } & \multicolumn{2}{c}{ Região da madeira } \\
\cline { 2 - 5 } Parâmetro morfológico & $\mathrm{I}$ & $\mathrm{II}$ & Cerne & Alburno \\
\hline Diâmetro do lume $(\mu \mathrm{m})$ & $8,94 \mathrm{a}^{(1,05)}$ & $7,83 \mathrm{~b}^{(1,00)}$ & $8,58 \mathrm{~A}^{(1,12)}$ & $8,20 \mathrm{~B}^{(1,18)}$ \\
\hline Fração Parede $(\%)$ & $52,37 \mathrm{~b}^{(4,63)}$ & $54,83 \mathrm{a}^{(4,09)}$ & $51,56 \mathrm{~B}^{(4,29)}$ & $55,64 \mathrm{~A}^{(3,80)}$ \\
\hline
\end{tabular}

(...) Desvio padrão da média. Mesmas letras em cada linha, dentro do mesmo fator, minúsculas para clone e maiúsculas para região da madeira, não diferem entre si, pelo teste $\mathrm{F}$ a $5 \%$ de probabilidade. 
O diâmetro do lume das fibras do clone I foi 13\% maior, enquanto a fração parede do clone II foi 5\% maior. Para a região de cerne verificou-se maior diâmetro do lume, já para o alburno, maior fração parede (Tabela 2).

Evangelista et al. (2010), ao estudarem dois clones de Eucalyptus urophylla, um aos 6 e outro aos 8 anos de idade, verificaram diâmetro do lume medindo 12,7 e $8,8 \mu \mathrm{m}$, respectivamente. Para um clone de Eucalyptus camaldulensis aos 10 anos de idade, esses autores verificaram diâmetro do lume de 10,8 $\mu \mathrm{m}$, valores próximos aos observados neste trabalho. Brisola e Demarco (2011) encontraram valores de 7,8 a 9,2 $\mu \mathrm{m}$ para o diâmetro do lume de madeira de três materiais genéticos de Eucalyptus aos seis anos de idade. Assim, os valores apresentados no presente trabalho são condizentes com os encontrados na literatura.

Observou-se uma relação diretamente proporcional entre fração parede e densidade básica da madeira. Ou seja, quanto maior a fração parede das fibras, maior a densidade básica e menos espaços vazios serão encontrados na madeira, como observado para a região do alburno. Contudo, variações na densidade da madeira dependem também das mudanças na frequência e diâmetros dos vasos (OLIVEIRA e SILVA, 2003), que não foram avaliados nesse estudo.

Para os parâmetros largura da fibra e espessura da parede, houve interação entre os fatores estudados (clone e região da madeira), conforme apresentado na Tabela 3. Dessa forma, realizou-se o desdobramento e avaliação do efeito de clone dentro de região na madeira e vice versa.

Observou-se diferença entre os clones, somente na região alburno, tanto para largura da fibra quanto para espessura da parede, sendo superiores no clone I. Já em relação às regiões da madeira, observou-se diferença significativa apenas na espessura da parede do clone I, cujo alburno apresentou valores superiores. Evangelista et al. (2010), observaram o aumento das dimensões das fibras ao longo do sentido medula-casca para a madeira de diversas espécies de eucalipto, corroborando com os resultados encontrados.

Evangelista et al. (2010) encontraram valores de largura das fibras de 21,3 e 19,3 $\mu \mathrm{m}$, para dois clones de Eucalyptus urophylla aos 6 e 8 anos, e 20,1 $\mu$ m para um clone de Eucalyptus camaldulensis aos 10 anos de idade. Já Brisola e Demarco encontraram valores de largura das fibras variando de 18,0 a $20 \mu \mathrm{m}$ para madeira de Eucalyptus aos seis anos de idade. Para a espessura da parede das fibras, Evangelista et al. (2010) verificaram, para os mesmos materiais genéticos já citados, valores médios de 4,3 a 5,3 $\mu$ m enquanto Brisola e Demarco encontraram valores de 4,9 a 6,1 $\mu \mathrm{m}$. Portanto, os valores observados neste trabalho corroboram com a literatura.

Não foi observado efeito significativo da interação entre clone $\mathrm{x}$ região na madeira para os teores de lignina (Tabela 4). A madeira do cerne apresentou $17 \%$ a mais de lignina em relação à madeira do alburno. Arantes et al. (2011) também verificaram, de modo geral, que os maiores teores de lignina se

Tabela 3. Largura da fibra e espessura da parede, em função dos clones e regiões da madeira.

Table 3. Fiber width and wall thickness as a function of the clones and the regions of wood.

\begin{tabular}{ccc|cc}
\hline \multirow{2}{*}{ Clone } & \multicolumn{2}{c|}{ Largura da fibra $(\boldsymbol{\mu m})$} & \multicolumn{2}{c}{ Espessura da Parede $(\boldsymbol{\mu m})$} \\
\cline { 2 - 5 } & Cerne & Alburno & Cerne & Alburno \\
\hline I & $18,04 \mathrm{aA}^{(1,57)}$ & $19,58 \mathrm{aA}^{(1,55)}$ & $4,50 \mathrm{bA}^{(0,53)}$ & $5,37 \mathrm{aA}^{(0,58)}$ \\
\hline II & $17,35 \mathrm{aA}^{(1,62)}$ & $17,31 \mathrm{aB}^{(1,43)}$ & $4,62 \mathrm{aA}^{(0,56)}$ & $4,88 \mathrm{aB}^{(0,46)}$ \\
\hline
\end{tabular}


rem entre si, pelo teste $\mathrm{F}$, a $5 \%$ de probabilidade. 
Tabela 4. Teores de lignina em função dos clones e regiões da madeira.

Table 4. Lignin content as a function of the clones and the regions of wood.

\begin{tabular}{|c|c|c|c|}
\hline \multicolumn{2}{|c|}{ Clone } & \multicolumn{2}{|c|}{ Região da madeira } \\
\hline I & II & Cerne & Alburno \\
\hline $32,35 \mathrm{a}^{(2,77)}$ & $30,71 b^{(3,24)}$ & $34,50 \mathrm{~A}^{(0,83)}$ & $28,56 \mathrm{~B}^{(1,11)}$ \\
\hline
\end{tabular}

(...) Desvio-padrão. Mesmas letras em cada linha, dentro do mesmo fator, minúsculas para clone e maiúsculas para região da madeira, não diferem entre si, pelo teste $\mathrm{F}$ a $5 \%$ de probabilidade.

Tabela 5. Teor de extrativos, em função dos clones e regiões da madeira.

Table 5. Extractives content as a function of the clones and the regions of wood.

\begin{tabular}{ccc}
\hline & \multicolumn{2}{c}{ Região da madeira } \\
\cline { 2 - 3 } & Cerne & Alburno \\
\hline I & $5,08 \mathrm{aA}^{(0,02)}$ & $2,30 \mathrm{bA}^{(0,18)}$ \\
\hline II & $4,23 \mathrm{aB}^{(0,07)}$ & $0,79 \mathrm{bB}^{(0,05)}$
\end{tabular}

(...) Desvio-padrão. Mesmas letras maiúsculas em cada coluna (clones) e minúsculas em cada linha (cerne ou alburno) não diferem entre si, pelo teste $\mathrm{F}$ a $5 \%$ de probabilidade.

concentram na região mais próxima à medula, ou seja, no cerne, e os menores teores são observados próximos ao alburno.

Considerando-se somente a composição química da madeira, o clone I e a região de cerne destacam-se. Isso porque a porcentagem de lignina é um importante parâmetro a ser considerado na destinação de clones de Eucalyptus para a carbonização da madeira, pois dentre os componentes químicos da madeira, a lignina é o que apresenta maior resistência à degradação térmica e influência de maneira positiva o rendimento gravimétrico em carvão vegetal (PROTÁSIO et al., 2012).

Vale ressaltar que as ligninas possuem elevada resistência à degradação térmica, quando comparadas à celulose e às hemiceluloses, devido ao seu alto nível de aromaticidade, elevado teor de carbono e ao tamanho e arranjo de sua estrutura (HAYKIRI-ACMA et al., 2010). A decomposição térmica de ligninas ocorre em uma ampla faixa de temperatura, podendo ser considerada como um conjunto de várias reações exotérmicas paralelas (MÜLLER-HAGEDORN et al.,2003). De acordo Yang et al. (2007), sua decomposição acontece lentamente, desde 100 a $900^{\circ} \mathrm{C}$, a uma taxa de perda de massa de aproximadamente $0,14 \%$ da massa $/{ }^{\circ} \mathrm{C}$. Segundo estes pesquisadores, em $450^{\circ} \mathrm{C}$, o resíduo sólido de lignina corresponde a cerca de $60 \%$ de sua massa inicial, indicando que a lignina é o componente químico da madeira mais importante quando se objetiva a produção de carvão vegetal.

Em relação aos extrativos, verificou-se interação significativa entre os fatores região da madeira e clone (Tabela 5).

Maiores teores de extrativos na madeira estão mais concentrados no cerne, para os dois clones avaliados. $\mathrm{O}$ aumento no conteúdo de extrativos, especialmente de polifenóis, está relacionado ao processo de cernificação (SILVA; TRUGILHO, 2003). O processo de cernificação é caracterizado pela morte das células do parênquima radial, consumo de amido, aumento no conteúdo de extrativos e tiloses, consumo de oxigênio e liberação de $\mathrm{CO}_{2}$ (HIGUCHI,1997).

Observou-se que os teores de extrativos, tanto para cerne, quanto para alburno, foram maiores para o clone I. A presença de tilos, gomas e outras substâncias extrativas que se depositam principalmente no cerne podem obstruir completa ou parcialmente seus vasos (SILVA et al., 2010). Portanto, de modo geral, quanto maior o teor de extrativos presentes na 
madeira menor será a sua permeabilidade. De acordo com Pereira et al. (2013a), o conteúdo de extrativos presentes na madeira atua como barreira natural à passagem de fluídos, o que irá influenciar na qualidade do carvão vegetal. Quanto maior a dificuldade para a liberação dos gases durante a carbonização, maior será o número de células rompidas, gerando um carvão vegetal friável e consequentemente com maior percentagem de finos (OLIVEIRA et al., 2013).

Há controvérsias a respeito da influência do teor de extrativos no rendimento em carvão vegetal para madeira de Eucalyptus. Por exemplo, Santos et al. (2011) encontraram relação positiva entre teor de extrativos e rendimento em carvão; Pereira et al. (2013b) encontraram relação negativa; já Zanuncio et al. (2014) não encontraram nenhuma relação entre extrativos e rendimento em carvão vegetal. Esses resultados indicam a necessidade de estudos mais aprofundados para determinar como cada classe de extrativo pode influenciar o rendimento em carvão vegetal. Provavelmente, esta contradição deve-se à pequena porcentagem de extrativos presente na madeira de Eucalyptus, variando, por exemplo, no presente trabalho, de 0,79 a $5,08 \%$, bem como da sua composição química que está relacionada com a estabilidade térmica. As madeiras de eucalipto contêm mais extratos polares, constituídos por taninos, gomas, açúcares, amidos e corantes (SHEBANI et al., 2008), sendo que a maior parte destes compostos degradam-se na faixa de 200 a $500^{\circ} \mathrm{C}$ (GRØNLI et al., 2002) e portanto, normalmente, não contribuem para o aumento do rendimento em carvão vegetal.

O teor de cinzas foi semelhante para os tratamentos avaliados (clones e regiões da madeira), cujo valor médio foi de $0,31 \%$, com desvio padrão igual a $0,14 \%$. De maneira geral, a composição elementar da madeira de Eucalyptus não varia muito, e os valores médios referentes às cinzas são de $1 \%$ (CARNEIRO et al., 2014).

Madeiras com elevados teores de compostos inorgânicos produzirão um carvão vegetal com maiores teores de cinzas, logo, o preferível é a utilização de madeiras com menores quantidades em sua composição. Segundo Reis et al. (2012) menores quantidades de compostos inorgânicos são desejadas também no carvão vegetal, pois os minerais não sofrem o processo de combustão e, consequentemente, diminuem o valor calorífico do carvão vegetal. O alto teor de cinzas no carvão vegetal ainda pode provocar acúmulo de impurezas no centro das peças de metal solidificado, causando variações nas propriedades do ferro-gusa (NEVES et al., 2011).

O poder calorífico superior (PCS) também não diferiu entre os tratamentos avaliados. O valor médio de PCS foi 4649 kcal.kg-1 $( \pm 54,30)$. De modo geral, o PCS da madeira de Eucalyptus apresenta pequena variação. Cita-se como exemplo o trabalho de Santos et al. (2011) que observaram que o PCS variou de 4.274 a $4.585 \mathrm{kcal} . \mathrm{kg}^{-1}$, para a madeira de diferentes clones de eucalipto aos 7 anos de idade, valores próximos ao encontrado neste trabalho.

Segundo Demirbas (2002), baixos teores de cinza, elevados teores de lignina e extrativos estão relacionados, simultaneamente, com o aumento do PCS. Assim, esperava-se que numa madeira com maior teor de lignina e extrativos fosse verificado também maior PCS. No entanto, tal relação não foi observada e relaciona-se, provavelmente, com as mínimas diferenças encontradas para a composição química elementar da madeira de diferentes espécies do gênero Eucalyptus. Ao desconsiderar as quantidades mínimas de nitrogênio e enxofre, a madeira de Eucalyptus é constituída de, aproximadamente, $45 \%$ de carbono, $6 \%$ de hidrogênio e $49 \%$ de oxigênio, conforme Pereira et al. (2013b). 


\section{Conclusões}

Para os dois clones de Eucalyptus camaldulensis avaliados, as porcentagens de cerne diminuem no sentido base-topo da árvore enquanto as porcentagens de alburno aumentam, sendo que o clone I tem maior proporção de cerne e o clone II, de alburno.

Maiores valores médios de densidade básica, fração parede, largura e espessura da parede das fibras estão associados à madeira de alburno. Já o cerne possui maiores valores médios de diâmetro do lume das fibras e teores de lignina e extrativos.

Visto que atualmente a densidade básica da madeira é o principal critério para a escolha de clones para a produção de carvão vegetal, e maiores porcentagens de alburno estavam associadas a maiores densidades, o clone II é o mais indicado para tal fim.

\section{Referências}

ARANTES, M. D. C.; TRUGILHO, P. F.; LIMA, J.T.; CARNEIRO, A.C.O.; ALVES, E.; GUERREIRO, M.C. Longitudinal and radial variation of extractives and total lignin contents in a clone of Eucalyptus grandis W.Hill ex Maiden x Eucalyptus urophylla S. T. Blake. Cerne, Lavras, v. 17, n. 3, p. 283-291, 2011 .

ARANTES, M. D. C.; TRUGILHO, P. F.; SILVA, J. R. M. da.; ANDRADE C. R.; Características do carvão de um clone de Eucalyptus grandis W. Hill ex Maiden x Eucalyptus urophylla S. T. Blake. Cerne, Lavras, v. 19, n. 3, p. 423-431, 2013.

ASSOCIAÇÃO BRASILEIRA DE NORMAS TÉCNICAS. NBR 8633: Carvão vegetal: determinação do poder calorífico. Rio de Janeiro, 1984. 13 p.

ASSOCIAÇÃO BRASILEIRA DE NORMAS TÉCNICAS. NBR 11941: Madeira: determinação da densidade básica. Rio de Janeiro, 2003. 6 p.

ASSOCIAÇÃO BRASILEIRA DE NORMAS TÉCNICAS ABNT. NBR 13999: Papel, cartão, pastas celulósicas e madeira - Determinação do resíduo (cinza) após a incineração a $525^{\circ} \mathrm{C}$. Rio de Janeiro, 2003. 4 p.
BRISOLA, S. H.; DEMARCO, D. Análise anatômica do caule de Eucalyptus grandis, E. urophylla e E. grandis x urophylla: desenvolvimento da madeira e sua importância para a indústria. Scientia Forestalis, Piracicaba, v. 39, n. 91, p. 317-330, 2011.

CARNEIRO, A. C. O.; CASTRO, A. F. N. M.; CASTRO, R. V. O.; SANTOS, R. C.; FERREIRA, L. P.; DAMÁSIO, R. A. P.; VITAL, B. R.; Potencial energético da madeira de Eucalyptus sp. em função da idade e de diferentes materiais genéticos. Revista Árvore, Viçosa-MG, v.38, n.2, p.375-381, 2014.

CASTRO, A. F. N. M.; CASTRO R. V. O.; CARNEIRO, A. de C. O.; LIMA, J. E. de.; SANTOS, R. C. dos.; PEREIRA, B. L. C.; ALVES, I. C. N.; Análise multivariada para seleção de clones de eucalipto destinados à produção de carvão vegetal. Pesquisa Agropecuária Brasileira, Brasília, v.48, n.6, p.627635, 2013.

DADSWELL, H.E. The anatomy of eucalypt wood. CSIRO Forest Products Laboratory, Melbourne, n.66, p.1-28, 1972.

DEMIRBAS, A. Relationships between heating value and lignin, moisture, ash and extractive contents of biomass fuels. Energy, Exploration \& Exploitation, v. 20, n. 1, p. 105-111, 2002.

EVANGELISTA, W.V.; SILVA, J.C.; VALLE, M.L.A.; XAVIER, B.A. Caracterização anatômica quantitativa da madeira de clones de Eucalyptus camaldulensis Dehnh. e Eucalyptus urophylla S.T. Blake. Scientia Forestalis, Piracicaba, v. 38 , n. 86 , p. $273-284$, jun. 2010.

FOELKEL, C.E.B., BARRICHELO, L.E.G., MILANEZ, A.F. Estudo comparativo das madeiras de E. saligna, E. paniculata, E. citriodora, E. maculatae E. tereticornis para produção de celulose sulfato. IPEF,Piracicaba, n.10, p.17-37, 1975.

GALVÃO, A. P. M.; JANKOWSKY, I. P. Secagem Racional da Madeira. São Paulo: Nobel, 1985. v.1.112 p.

GOLDSCHIMID, O. Ultraviolet spectra. In: SARKANEN, K. V.; LUDWING, C. H. (Eds) Lignins. New York: Wiley Interscience, 1971. p. 241-266.

GOMIDE, J. L.; DEMUNER, B. J. Determinação do teor de lignina em material lenhoso: método Klason modificado. $\mathbf{O}$ Papel, v. 47, n. 8, p. 36-38, 1986. 
GRØNLI, M. G.; VÁRHEGYI, G.; DI BLASI, C. Thermogravimetric analysis and devolatilization kinetics of wood. Industrial \& Engineering Chemistry Research, v. 41, p. 42014208, 2002.

HAYKIRI-ACMA, H.; YAMAN, S.; KUCUKBAYRAK,S. Comparison of the thermal reactivities of isolated lignin and holocellulose during pyrolysis. Fuel Processing Technology, v.91, p.759-764, 2010.

HIGUCHI, T. Biochemistry and molecular biology of wood. Berlim: Springer-Verlag, 1997. 362 p.

HYAMS, D. Curve Expert Version 1.4: Universidade Federal do Rio Grande do Sul. 2009.

IAWA COMMITTE E.IAWA list of microscopic features for hardwood identification. IAWA Bulletin, Leiden, v.10, n.3, p.221-332, 1989.

INDÚSTRIA BRASILEIRA DE ÁRVORES (BRAZILIAN TREE INDUSTRY) - IBÁ, Relatório ano base 2014. $64 \mathrm{f}$, 2015.

MÜLLER-HAGEDORN, M. et al. A comparative kinetic study on the pyrolysis of three different wood species. Journal of Analytical and Applied Pyrolysis, v.68, n.1, p.231-249, 2003.

NEVES, T. A.; PROTÁSIO, T. P.; COUTO, A. M.; TRUGILHO, P. F.; SILVA, V. O.; VIEIRA, C. M. M. Avaliação de clones de Eucalyptus em diferentes locais visando à produção de carvão vegetal. Pesquisa Florestal Brasileira, Colombo, v. 31, n. 68, p. 319-330, 2011.

OLIVEIRA, A. C.; CARNEIRO, A. C. O.; PEREIRA, B. L. C.; VITAL, B. R.; CARVALHO, A. M. M. L.; TRUGILHO, P. F.; DAMÁSIO, R. A. P. Otimização da produção do carvão vegetal por meio do controle de temperaturas de carbonização. 2013. Revista Árvore, v. 37, n. 3, p. 557-566. 2013.

OLIVEIRA, J. G. L.; OLIVEIRA, J. T. S.; ABAD, J. I. M.; SILVA, A. G.; FIEDLER, N. C.; VIDAURE, G. B.; Parâmetros quantitativos da anatomia da madeira de Eucalipto que cresceu em diferentes locais. Revista Árvore, Viçosa, v.36, n.3, p.559-567, 2012.

OLIVEIRA, J. T .S.; SILVA, J. C. Variação radial da retratibilidade e densidade básica da madeira de Eucalyptus saligna Sm. Revista Árvore, Viçosa, v 27, n. 3, p. 381-385, 2003.
PAULA, J. E. Caracterização anatômica da madeira de espécies nativas do cerrado, visando sua utilização na produção de energia. Cerne, Lavras,v. 11, n. 1, p. 90-100, 2005.

PEREIRA, B. L. C.; OLIVEIRA, A. C.; CARVALHO, A. M. M. L.; CARNEIRO, A .C. O.; SANTOS, L. C.; VITAL, B. R. Qualityof Wood and charcoal from eucalyptus clones for iron master Use. International Journal of Forestry Research, v. 2012, p. 1-8, 2012.

PEREIRA, B. L. C.; OLIVEIRA, A. C.; CARVALHO, A. M. M. L.; CARNEIRO, A. C. O.; VITAL, B. R.; SANTOS, L. C. Correlações entre a relação Cerne/Alburno da madeira de eucalipto, rendimento e propriedades do carvão vegetal. Scientia Forestalis, Piracicaba, v. 41, n. 98, p. 217-225, $2013 \mathrm{a}$.

PEREIRA, B. L. C.; CARNEIRO, A. de C. O.; CARVALHO, A. M. M. L.; COLODETTE, J.L.; OLIVEIRA, A. C.; FONTES, M. P. F. Influence of chemical composition of Eucalyptus wood on gravimetric yield and charcoal properties. Bioresources, Railegh, v. 8, p. 4574-4592, 2013 b.

PROTÁSIO, T. P.; TRUGILHO, P. F.; NEVES, T. A.; VIEIRA, C. M. M. Análise de correlação canônica entre características da madeira e do carvão vegetal de Eucalyptus. Scientia Forestalis, Piracicaba, v. 40, n. 95, p. 317-326, 2012.

PROTÁSIO, T. P.; COUTO, A. M.; REIS, A. A.; TRUGILHO, P. F.; GODINHO, T. P.; Potencial siderúrgico e energético do carvão vegetal de clones de Eucalyptus spp. aos 42 meses de idade. Pesquisa Florestal Brasileira, Colombo, v. 33, n. 74, p. 137-149, 2013.

REIS, A. A.; PROTÁSIO, T. P.; MELO, I. C. N. A.; TRUGILHO, P. F.; CARNEIRO, A. C. Composição da madeira e do carvão vegetal de Eucalyptus urophylla em diferentes locais de plantio. Pesquisa Florestal Brasileira, Colombo, v. 32, n. 71, p. 277-290, 2012.

SANTOS, R. C.; CARNEIRO, A. de C. O.; CASTRO, A. F. M.; CASTRO, R. V. O.; BIANCHE, J. J.; SOUZA, M. M. de.; CARDOSO, M. C.; Correlações entre os parâmetros de qualidade da madeira e do carvão vegetal de clones de eucalipto. Scientia Forestalis, Piracicaba, v.39, n.90, p.221-230, 2011.

SHEBANI, A. N.; VAN REENEN, A. J.; MEINCKEN, M. The effect of wood extractives on the thermal stability of different wood species. Thermochimica Acta, v. 471, p. 43-50, 2008. 
SILVA, D. A.; TRUGILHO, P. F. Comportamento dimensional da madeira de cerne e alburno utilizando-se a metodologia de análise de imagem submetida a diferentes temperaturas. Cerne, v.9, n.1, p.056-065, 2003.

SILVA, M. R.; MACHADO, G. O.; DEINER, J.; CALIL JUNIOR, C. Permeabilidade e Mensuração do eucalipto brasileiro. Pesquisa de Materiais, v. 13, p. 281 - 286, 2010.

STATS OF TINC. Statistica data analysis system version 8.0. Tulsa: Stats of tinc., 2007.

TAPPI - Technical Association of the Pulp and Paper Industry. TAPPI test methods T 204 om-88: solvent extractives of wood and pulp. In: TAPPI Standard Method. Atlanta, USA. Cd-Rom, 2001.

TAPPI - Technical Association of the Pulp and Paper Industry. TAPPI test methods T $264 \mathrm{om}-88$ : preparation of wood for chemical analysis. In: TAPPI Standard Method. Atlanta, USA. Cd-Rom, 2001.

TAPPI - Technical Association of the Pulp and Paper Industry. TAPPI test methods T $257 \mathrm{~cm}-85$ : sampling and preparing wood for analysis. In: TAPPI Standard Method. Atlanta, USA. Cd-Rom, 2001.

TOMAZELLO FILHO, M. Variação radial da densidade básica em estrutura anatômica da madeira do Eucalyptus globulus, E. pellita, E. acmenioides. Instituto de Pesquisas e Estudos Florestais, Piracicaba, n. 36, p. 35-42, ago.1987.

YANG, H.; YAN, R.; CHEN, H.; LEE, D. H. ; ZHENG, C. Characteristics of hemicellulose, cellulose and lignin pyrolysis. Fuel, v. 86, p. 1781-1788, 2007.

ZANUNCIO, A.J.V.; CARVALHO, A.G.; TRUGILHO, P.F.; MONTEIRO, T.C. Extractives and energetic properties of wood and charcoal. Revista Árvore, Viçosa, v. 38, n. 2, p. 369374, 2014. 